\title{
El argumento de "Hamlet"
}

\author{
pos
}

\section{Carlos Eduardo Zavaleta}

Pensar en vidas eminentes que hayan dejado huellas en países e individuos y corran por ahi en volúmenes cargados de arte o historia, es siempre una ocasion para mezclar juicios que todos sabemos con otros menos difundidos, y aun con otros que son apenas conjeturas creadas por ia ausencia de notıcias ciertas sobre pequeños hechos que, por fortuna, son simples detalles borrosos en un mar vasto y limpio. Si asi sucede en pláticas callejeras o jugosos libros de ensayo, ahora debemos mezclar también juicios resabidos con otros escondidos, aunque certeros, y además, con la confesión abierta de que todos, humildes y eruditos, ignoramos algunas minucias sobre el hombre (Shakespeare) o el personaje (Hamlet), sin quèbujestre cevoción】por anbos se empañe en lo mínimo. Por lo demás, Puna Facultad de Letras como ésta se nutre ya sea de la polifacética vida de los creadores, o ya de ia otra vida, no menos polifacética, de los personajes forjados por aquéllos. Hermosa existencia de una institución en que la fantasía vale tanto como la verdad. La nobleza ejemplar del poeta o novelista exige que se hable más de sus criaturas que de si mismo; cuanto más independiente sea un personaje, más feliz vive su autor; por ello, he de hablar más de Hamlet que de Shakespeare, como si este príncipe, pensando en la "inmensa noche, que es para tantos el inmenso día", al decir de Chocano, se hubiera libertado de Shakespeare al punto de convertirse, según dijo la ironía de Joyce, en padre $y$ no en hijo de su dueño. He aquí la vida del hombre a quien Ofelia (ella era "una rosa de mayo" y "estaba hecha de esos hilos con que se tejen los sueños") llamó "el ojo del cortesano, la lengua del letrado, la espada del guerrero: la rosa y la esperanza de este 


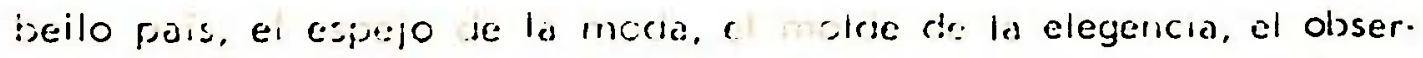
vado cie tocio los cestervaciores $(1)$, el principe que en vez cie suirir conflicios pentlecs y de cistado, suirio los mas duros conflictos cel corazon humalle, ; sil perder jamas el fuicio, vivió escentas su. ícientes pera volverse icco, ccirc el mar y el viento, cuando se cisputan entre si cual e. mas fuerte. I me place, en verciad, tocar el terria cie este hans:are y de su estirpe ent una tribuna ocupada antaño por estuciarie, perciele, yue e volvieron erucitos, asi como los jóvenes se vecticen numbres, leyendo aqui sus palabras, táles como Lonstantino balazar y Luis firro-Quesacia, y por maestros extranjeros corrio Durek Traversi, quiencs comprobaron que, en San Marcos y tccia lo intelectualicici peruana, Hamlet es tenicio a la vez por un trágicc pocta y un solido personaje.

Se nos ha cicio que el nemibre $y$ el argumento de Hamlet reisasan la vida cie Sinaresprare y so hunden inuy lejos, inclusive en el siglo $\times 11$, en las páginas de la Gesta danica, escrita por Saxo Gramático o Sajón el Letracio, y que en la tercera y cuarta partes de ella hay una historia cie Amletin, y se nos ha añadido, sobre todo en los últimos tiempos, ciye la versión de Saxo Gramático es solo una de las dos versienes medievales que subsisten: ia otra sería la historia o "sage" de Armbales, llamado también Amlodi, que representaria un argumento más antiguo que el de Saxo, si bien consta en manuscitcs más 0 menos contemporáneos al Hamlet de Shakespeare. Aclemás, Jägrersióncide bároo revelaria el conocimiento de "una historia analoga, la de Lucio Junio Bruto, el mítico héroe romano que expulsó a los tarciuinos de Roma y libertó para siempre a esa ciudad de la inonarquia" (2); la primera versión de dicha historia de Bruto se hallaría en Las antigujedades romanas, de Dionisio de Halicarnaso, aunque, en formo abreviada, aparecería tanto en los historiadores Tito Livio, Ovidio y Dion Casio, como en otros historiadores medievales. Junio a esos tres argumentos, sabemos

(1) La mayoria de ias citas; de fiamlet son tomaclas de la traducción de Astrana Marín, y scilo de vez ea cuando he recurriclo a la versión cle Salvador de Madariaga, o a uno adaptación mía, sobre la base de ambas versiones.

(2) Charles W. Eckert, The Festival Siructure of the Orestes-Hainlet Traditien, Compararive Literaturs. Vol. XV, N: 4, Otoño, 1963), 327. 
ciertamente que en 1582 se publicó en París el quinto voiumen de las Historias trágicas, de Belleforest, volumen en que aparece la "historia tercera", donde el "ruso Amleth, quien fue luego rey de Dinamarca, vengó la muerte de su padre Horuvendille, asesinado por Fengon, su hermano, y otros sucesos de su historia" (3). En resumen, aparte de interminables fuentes adicionales que nos ahogarían en cumplidos detalles, pero no en deleites artisticos, existen cuatro fuentes diversas, ordenadas asi, de la más antigua a la más reciente: (a) la historia romana de Bruto, (b) el argumento de Ambales, (c) la historia de Sexo, y (d) la de Belleforest. Ellas juntas pintan el retrato de Hamlet pre-Shakesperiano, vinculado, dice Gilbert Murray, con mitos y rituales del héroe griego Orestes, ya que ambos argumentos tradicionales tendrían un origen común en el antiguo rito del asesinato periódico de un rey; o mejor, como lo señala Charles W. Eckert (4), "los tres héroes más importantes de aquellas historias, o sean el griego Orestes, el romano Bruto y el escandinavo-cristiano Hamlet, se vincularían todos con los festivales de Año Nuevo, Y especialmente con los ritos purgativos y de iniciación que se efectúan por este tiempo".

Eckert ha analizado con minuciosidad estos argumentos y los lazos habidos entre sí. He aqui sus conclusiones:

1) EBilodásolaseversiohes, Tepadregdel héroe (o el padre del hermano) os asesinadopor un tío que hereda el trono y

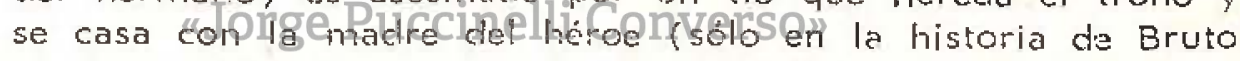
el tio no se casa con la reina). Sabiendo el héroe que, como hijo del rey difunto, está en peligro. se finge loco y engaña a su tio presentándose como alguien demasiado irrazonable para constituif una ameraza. En las versiones de Saxo. Ambales y Belleforest, llega a adquitir un estado casi animal, mirancio oblicuamente como un mono, cacareando como una gallina, y rodando sobra el fanco o la ceniza de modo ofensivo aun a la vista y olfato de los sirvientes.

2) Excepto en la de Bruto, en las demás versiones es un hombre demasiado misógino, que arroja fuego a las criadas -en el argumento de Ambales llega a levantar en vilo a su madre y sostenarla por sobre el fuego de la cocina. La esce-

\footnotetext{
(3) Salvador de Madariaga, El Hamle: de Shakespeare (Buenos Aires: Editorial Sudamericana), p. 13.
}

(4) Eckert, op. cit. 
na del dormitorio eque aparece on Shakespeare, donde la reina Es reprochada, echucicla a lugrimas por su hijo, aparece tam bién en las antiguas versiones, si bien en el argumento de Ambales el hercr se coniente con ser sarcástico. hacer ruidos desagradables y amenazar a su madre blandiendo un arpón.

3) En icdas las versicnes (excepto en la de Brulo), el héroe mata a uno de los consejeros del rey, escondido previamente en la alcoba de la reina a fin de espiar su plática con el hijo y descubrir si esic, en verdad, es insano o conspira contra el rey. En Ambaiss, Saxo y Belleforest, el consejero recibe una astacada en is escondite, es arrastrado fuera de la alcoba, y luego despedazido y hervido en agua, para ali. meniar a los cerdos.

4) En iodas las versiones (excepto en la de Bruto) a la muerte dél corisejere sigue el destierro del hérce hacia una corte amiga adonde viaja en compañia de dos sirvientes del rey, cisienes llevan una carta instruyendo al monarca exiranjero para darl': vejere El héroz ciescubre la carta, la substituye por otra pidiendo la muerte de sus acompañantes, y luego permanece un año (según Sayc y Belleforest) o tres años (según Ambales) antes de volver. En la historia de Bruto, donde no aparece la madre ni hay asesinato del consejero, se realiza el viaje con clos hijos ciel rey hasta Delfos, y aqui Bruto triunfa sobre sus acompeñantes al interpretar correctamente un orácuio de la pitonisa y al cumplirlo en secreto, con lo cual asegura su derecho de sucesión al trono. Todas las versiones comparten, como se vé, el morivo del viaje peligroso, de donde el héroe vuelve triunfante.

5) En Sayo y Belleforest el herce vuelve" a su hogar, retoma el traje mugriento que había usado. llega a la sala en que se celebran sus propias exequias, y clespués che embriagar a todo el mundo incendia la sala y mata al rey. En la historiz de Ambales ocurre lo rismo, excepto que el héroe no vuelve a un funeral sino a una celebración de Navidad, incendiando después la sala en la noche de Año Nuevo. Por su parte, Bruto subleva al pueblo de Roma a fin de cerrarle las puertas a Tarquino, lanzándolo así al exilio.

De todos los argumentos, el de Ambales es el menos raciorializado aunciue rics dé el indicio más seguro hacia una tradición mucho más amplia, que englobe a las demás. Durante la locura cle Ambales, a veces fingida y a veces real, éste anima una increible serie de aventuras, espanta enloquecido un rebaño de ovejas, vence a un gigante de las cavernas, levantándolo del suelo y aplastándolo, domina a otro ser salvaje cuya capa de gnomo usa después, suministra comida diaria a sasenta mil cerdos, y 
tiene por cada compañía a un mago enano. En gran parte, !as aventuras cle este hijo de la reina Amba son idénticas a las de Heracles, hijastro de la diosa Hera. El mito de Heracles es uno de los más notables y primitivos cle la antigüadad griega, y la tradición heroica que él representa dibuja ol modelo para muchos circs herces, sean Dionisio, Ayax, Teseo, Odiseo, o en fin, ccrrando el circulo, el propio Orestes. (5)

En medio de estas investigaciones, la crítica ha pasado a buscar vínculos triangulares entre mitos, rituales y un específico período festival, y también un fondo común de los festivales de Año Nuevo, donde los ritcs no sólo purifican, sino extirpan y recrean, a más de anular el pasacio con sus males y culpas, modelando una nueva época. Al principio y fin de este largo recorrido, dable es cotejar el Hamiet de Shakespeare con la Orestiada de Esquilo, en vista del común impulso juvenil y moralizante, y de otras analogías del argumento, por más que haya profundas diferencias en la situación mutua de los personajes, hundidos como están en pathos trágicos diversos, como diversas son las épocas y los vínculos entre hombres y dioses, reflejados en ambas obras.

Sin embargo, estas comparaciones sobre textos griegos, latinos y franceses no deben hacernos olvidar el ejemplo más directo de unas piezas teatrales contemporáneas a Shakespeare, donde el arqumento tradicional había encarnado ya en una fórmula escénica, gustada y aplaudidả por éb público dy juzgada por los autores como una convención más o menos respetable.

A ese público isabetino le complacian los temas de venganza. El favorito Thomas Kyd había escrito, es posible, antes de 1588, La tragedia española, esa madre de las piezas de venganza. Aquí el brazo, la espada y el fuego de la justa venganza eran blandidos por el viejo Jerónimo, un noble español que había perdido a su amado hijo Horacio, salvajemente asesinado cuando cortejaba a la princesa Belimperia. La pieza se abre con un prólogo a cargo del fantasma del joven, contando aquel pasado. La fiel princesa y el viejo deudo jurando vengarlo; la trama discurre así en un doble plano, el de la locura fingida de Jerónimo, ansioso de castigar el crimen, $y$ el de los nuevos pasos del asesino, quien todavia pretende la mano de Belimperia, obligada a desposar al hombre que la privó de su amante. En una solución feroz, mezclando el teatro (5) Eckert, op. cit., 324-325. 
con la vida real (artiáicio tambien clecisivo en el Hamlet de Shakespeare, para ic!enificar al criminal), Jerónimo propone que en la boda se represente uria trageciia. Asi, la suerte de los invitados se define en un sangriento espectáculo en que ellos son muertos $u$ obligados a matarse; pero el desmedido sacrificio va más allá de la expiación de los pecados: la atmósfera de horror es una herencia de las magnéicas págiras de Séreca.

El argumento de las piezas de venganza sigue un modelo consabiclo. Einpisza con el crimen, generalmente un asesinato provocado por diversos móviles; continuja con el "deber de venganza"


problema de identificar al asesino y halla multitud de obstáculos in su marcha, hasia que, sil ei úlimo acto, ei criminal recibe su espectacular merecicio, y puesto que el público gozaba con las tragedias impresionantes, el vengador y sus cercanos coloboradores perecian juntos en un inolvidable baño de sangre, catástrofe cuya ferocidad sólo podia ser atenuada por la maestría del artista, para quien, en el fondo de dicho espectáculo, había por cierto una moralidad. La venganza, según esta costumbre escénica, era a la vez un deber piadoso y un acto de salvaje justicia. Según G. B. Harrison (6), no se buscába seguil la ley del ojo por ojo y diente por diente, sino los dos ojos por uno y toda la quijada por un diente, con el añadido de tormentos físicos y mentales para despachar al culpable al infierrio, en una condenación que fuera también espiritual y eterna.

Harrison mismo recuerda el antecedente de dos piezas de John Marston, ambas escritas en 1599, cuyas similitudes con Hamlet se explican porque el tema flotaba en el aire que respiraban los dramaturgos de la época, aunque nos pongan en la alternativa de decir que $c$ bien Shakespeare fue influido por Marston, o bien Hamlet fue escrito en su mayor parte antes de 1599.

Una obra de Marston, titulada La venganza de Antonio, es de veras interesante. Aquí el héroe Piero entra en el escenario con sus armas bañadas en sangre, un puñal y una antorcha en las manos, seguido por su predilecto Strotzo, que lleva en las suyas una ex-

(6) El capitulo "Hamlet" dal libro de Harrison, Shakespeare's Tragedies, es una guía frecuente de lo que se dirá en seguida. 
plicativa soga. Piero ha tenido una tarde muy feliz: ha envenenado a su rival Ancirugio, ha apuñalado al cortesano Feliche, colgando el cadáver en la alcoba de su hija Melida, y espera ansioso que a la mañana siguiente llegue la duquesa María, ex mujer de Andrugio, para vivir clefinitivamente con ella. Apenas entierra a la víctima, Piero le hace fugazmente el amor a María, sin saber que la venganza contra él ya empezó a tejer sus firmes redes. Cuando Antonio, el hijo de Andrugio, llegue a rendir un tributo a la tumba de su padre, se yergue el fantasma de éste, le revela su asesinato, clama venganza y !e advierte que su madre, la duquesa María, ha cediclo ante Piero.

En el escenario, Antonio se cruza con el asesino y'con su hijo, Julio, quicn, por ser amigo de aquél, se queda a platicar cordialmente; pero Antonio, pensando que bien vale el cambio de un hijo por su propio paciie, le corta a Julio la garganta, y sólo a medias satisfecho, esparce la sangre scbre la tumba. Por la noche, Maria halla en su cama el fantasma de su difunto marido que le reprocha su liviandad. Y poi otra parte, Melida, hija de Piero, es acusada cle adulterio for haberse hallado en su alcoba el cadáver del cortesano Feliche. En medio del tejido de asesinatos e intrigas, ella lucha por su honor, pero te mienten diciéndole que Antonio ha muerto; entonces la delicada e ingenua Melida sucumbe de un ataque al corazón. Hastá que llega la catáștrofe final, la burla macabra que Antonio prepara a piero. Este supone que va a casarse con Maria en un baile de máscaras donde Unos cortesanos le piden de súbito que deje en libertad a sus siervos, pues "desean honrarlo ellos mismos"; en el paroxismo de felicidad, Piero accede a todo $y$ queda a merced de Antonio y sus einmascarados secuaces, para quienes empieza el placer de una carnicería. Ellos atan a Piero, le arrancan la lengua, le presentan una vianda con los miembros de Julio (atrocidad empleada ya por Shakespeare en Tito Andrónico), alzan sus estoques, lo persiguen $y$ hieren con una lentitud estudiada $y$ cuchillera. Así, en el último instante, el fantasma de Andrugio, que ha contemplado la escena, se retira complacido.

Toda esta gran herencia de temas y espectáculos recibe Shakespeare. En sus manos, la "venganza" gana en riqueza, amplitud y profundidad. El vengativo hijo Hamlet, matando al nuevo rey, mata también a una especie cle padre; él mismo queda sujeto a la 
ley de venganza. No difiere del vengador Orestes, sujeio también a los tormentos de la culpa. Pero esta modificación del tema cambia asimismo el número de vengadores: Hamlet es el vengador que saltará sobre Claudio, pero Laertes es el vengador que matará a Hamlet. Las dos venganzas ocurren al mismo tiempo, en una nueva señal de la maestría de Shakespeare. Ya el Hamlet vengador, por eso, no se parece al vengador Antonio de la obra de Marston; Antonio queda vivo y libre, sin que lo persigan las furias o las sombras de su crimen, satisfecho y sonriente, como héroe primitivo y grosero que es. Hamlet no podía quedar vivo, pues el mal que habia envuelto a sus padres, en una u otra forma. debia aplastar igualmente a este nuevo regicida, como había cle aplastar a Clau. dio, otro regicida, y a Laertes, que osará levaniarse contra el príncipe heredero.

Laertes exige una mención aparte. Miembro de una familia otrora feliz, cuya desgracia empieza por un azar del destino (Hamlet mata sin premeditación a Polonio) y continúa con el desdichado espectáculo de su hermana demente, Laertes es personaje decisivo en la obra. " $O$ Oh rosa de mayo, preciada niña, amorosa hermana, dulce Ofelia!", exclama al verla enloquecida. Su ternura es profunda; su cólera, justa; su intriga, efectiva y torcida; su arrepentimiento, sincero. La muerte de su hermana colma para él todas las medidas; muerte iquei latreina describequeasucedió "mientras cantaba estrofas de antiguas tonadas" cuando sus "vestidos cargados con el peso del gimiente arroyo" adonde había caído, "arrastraron pronto a la infeliz a una muerte cenagosa, en medio de sus dulces cantos". Verdad que el iracundo y a su modo justiciero Laertes habia lanzado ya su atroz grito de furia contra Hamlet: "Cortarle el cuello dentro de la iglesia!". Pero su cólera y sus maquinaciones en compañla de Claudio para matar al príncipe, su deslealtad en la escena del duelo a floretazos, son culpas suficientes para ser arrastrado también en la mortandad.

$Y$ por fin, el manto de la venganza se extiende aún más y cubre también a la reina, la mujer que tuvo un primer marido" tan afectuoso... que no permitía a los vientos del cielo rozar con mucha violencia su cara", y que, sin embargo, por su ingratitud y su traición al unirse con un "risueño y maldito infame", es menos que un animal, pues "una bestia incapaz de raciocinio hubiera sen- 
tido un dolor más duradero", según dice el hijo de ella. Por una sutil ironía, puesto que la reina es menos perversa que débil ("indecorosa, no criminal", la llama Eugenio María de Hostos), ella muere por un accidente, por un revés de fortuna que sólo adquiere virtud tránica cuando se parece a una intención - método poco empleado en la antiạuedad clásica. Recordad el ejemplo que nos evoca Alfonso Reyes, cuando la estatua de Mytis, en Argos, cae durante un espectáculo sobre el responsable de la muerte de Mytis. De modo semejante, la copa envenenada llega por accidente, pero como si cumpliera una intención, a los labios de esa mujer que con sus desviados actos auitó "la rosa de la hermosa frente de un amor puro" $y$ puso ahi una llaga.

Tantos actos venqativos que abaten a un culpable cierto. como es Claudio; a una culpable incierta, amada y odiada por su víctima, como la reina; a moralistas desaforados, más o menos pensativos, como Hamlet y Laertes; a un espía tonto como Polonio; a siervos indignos, como Guildenstern y Rosencrantz; y a flores inocentes, como Ofelia, precisaban de un orden civilizado de presentación, por más que al público isabelino le gustaron los espectáculos macabros. Unos debian morir antes del acto final, donde hay muchos cadáveres. En el camino van quedándose vertos Polonio y ambos siervos; y además, dehía existir una dama joven, inevitable en las piezas de venqanza. Uno de los excelentes acieftos de Shakespeare consiste en que la dama iovejosea hermana del hombre que mata a Hamlet $\checkmark$ en que ella muera antes del acto final, pues en esta clase de obras el amor no debía ser el tema principal; $v$ es iqualmente un acierto que ella, envuelta en una " vaquedad divina" (lo repite Hostos), enloquezca de veras, no finaidamente como Hamlet, ya que siempre habia locos en las piezas de venganza $y$ ellos eran una parte del éxito.

Tantas modificaciones en la trama y los personajes plantearon algunos problemas serios. El problema nacido de la coexistencia de dos vengadores fue resuelto, hemos dicho, hallando una misma escena para deshacerse de ambos; con el estoque envenenado la escena es repentina y efectiva. Casi al mismo tiempo, entre ironfas y sorpresas, la reina bebe la copa destinada para su hijo. $Y$ en los minutos postreros de la descomunal violencia mueren Claudio y Hamlet. ¿Se habrá deshecho la familia real de Dinamarca? ¿Se hun- 
dirà el reino en el cass" ¿Bastará qua el "sencillo, noble y exce. lente Horacio", según palabras de Gontine, un simple amigo del bando en minoria deniro de la casa real, subsista piri contar la historia, ya que ne para revil a un arjo o necesitamos a otre

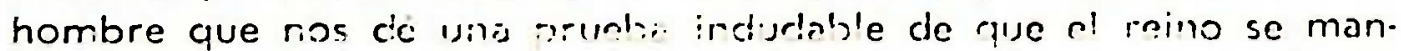
tiene? Menudo probleme resuslio sabiariente con la pre-encia del joven Fortimbrás y su ejército, enntidos yo descle el primer acto. Asi habrà alguien, con maycr auto-ida-! oue Ho-ario, para dirigirse a los especiadores y explicar!ns rué nasará clespurs, alruien que ordenará grandes y justos furerales para Hamlet y dará la impresión de que el estado de Dinamerca, on vez de hundirse, queda al fin en buenas mancs. Y el tercer pichlema, el de -xplicar cómo se entera el hijo de la muerte de su pad-e, is ha rr-uelta ya la tradi. ción del viejo argumento: él sentera del crimen por el fantasma. Ninguna pieza de venganza podia ser completa sill un fantasma, por lo menos.

Shakespeare, en una palabra, runveva y transforma los elernentos gastados de un vaste melodrama. Sin cluda, sus principales cñadidos al tema son:

(1) los dos vengacicies en vez cle ur.o solo;

(2) la historia de Fortiniás el joven, parale!a al descubrimiento y castigo del critrena he ahí el inundo político de la obra;

(3) la mezola de thechosljerversosicon los comentarios que de ellos hace Hamlet, un intelectual con profunda sensibilidad poética: siendo en su maycría nonćlogos, dichos comentarios sustituyen al antiguo coro griego cive subrayaba las acciones pasadas 0 presagiaba el futuro, si bien surgen también en los diálogos con Horacio, otro intelectual; debido al lenguaje rico, violento y tierno de los comentarios, el argumento adquiere una grancleza que engloba, además cle los hechos perversos vistos en escena, la perversidad de toda la naturaleza humana, analizada por el gran juez de una época. La fingida locura del personaje no es más que una ocasión para que este juez amargado y sardónico fustigue a los hom. bres y a su medio;

(4) la oposición entre Hamlet y la familia de Polonio, aliado del rey, que termina en la intima alianza del tío asesino con Laertes, lo cual hace aumentar el peligro para Hamlet; $y$ 
(j) f́nalmente, hay un cambio en la situación personal de la dama joven, quien ya no es la hija del asesino, como en La ven: ganza de Anronio, sino un miembro de esa familia de Polonio que ha de contribuir a la caicia del héroe.

Estos añadidos no soi todos, claro esiá; por encima de ellos hay que subrayar la criginalidad con que Shakespeare ordena $y$ divide el tema en ties portes: la primera, que dura todo el primer acto, doncie el estacio de viga desconfianza da paso a la sospecha, merced a la ceciaracion del fantasma; la segunda, que abarca el segundo y tercei actos, clonde Hamlet prueba la culpabilidad de Claudio; y la tercera y última parte, donde Hamlet y Laertes se vengan mutuamente. En la sucesión cie estas partes diferenciadas, el argumento avanza a través de oijstáculos que en la critica aristotélica se llaman accicientes; pues bien, a pesar de que tales incidentes se aiejan de los cánones aristotélicos, la obra en conjunto adquiere una caiidaci comparáble a ia alcanzada por la tragedia griega. Verciad por ejemplo. que Aristóteles aconsejaba que las peripecias no ciebian multiplicarse, ni molestar la unidad cle acción, al conspirar contra la probabilidad clel tema. Verdad que la aparición del fantasma, hecho de por sí improbable, fue aceptada como una convención clel teatro isabelino $y$ es fácilmente aceptada por nosotros descle el punto cle vista artístico y no, desde luego, ideológico. Pero, una por una las tres intervenciones del fantasma son dramáticas, oportunas y funcionales. Por otra parte, Aristóteles afirmaba que la anagnórişs eracuincaso cúbito'sde' la ignorancia al conocimiento, pero que, de todos los tipos de anagnórisis, el de cleciaración era uno de los rilenos eficaces, puesto que no brotaba de la acción. Sin embargo, Shakespeare emplea esta anagnórisis de declaración cuando el fantasma revela el crimen a Hamlet. Es una anagnórisis anticipada y preparatoria, débil si se quiere, aunque en seguida en la escena de la representación del "Asesinato de Gonzago", tenemos la segunda y verdadera, esta vez del tipo de choque patético, cuando la meinoria de Claudio lo vende como a un criminal. En cuanto a los sufrimientos o pathos trágico, exhibiciones cle hechos patéticos tales como muertes, torturas, riñas y asaltos. Aristóteles pedía que se nos dieran "hasta donde lo toleren la materialidad escénica y la resistencia media a la brutalidad del acto". Los sufrimientos pueden ser escénicos o extraescénicos, según se 
les exhibe o no frente al público. En riamlet it exinben abiertamente, en una muestra de sūngre y violencia que, bien conirolacia como está, es un espectáculo ascrnioroso de la iiracionuidiaci humana en vaivén continuo irente a la rüzón. Respecto a los coros, el último tipo de inciderites, hemcs dicho ya que Shakespeare los moderniza, aprovechando su condición de válvula de la catharsis que tenian en el teatro griego, y en sustitución de ellos nos cla los comentarios pocticos e irónicos clel protagonisia.

Por lo demás, aquel principio cie jerácquia segun el cuai el argurnento es la esencia de la tragecia y su primer elemento interno, situado por encima de los personiajes y pensamientos, es respetado a medias par Shakespeare, uvil cuando a veces siga la tendencia renacentista a sobrestimar el personaje.

Sabemos que la revelacion wel uigunientio a los espectaciores ell una sala de teatro se cia uil cieric ordien, cie lo externo a 10 interrio. Primero esiá el espectecuio, la rupresentacioni misma; ivego, ei lenguaje y lus pensamlentos, à trävés de los que conocemos a los personajes; y iirialriente, súio poi este camino podemos abarcar toda la tiama. Si la representacion varia según las epocas, gustos y nácionalidades de públicos y directores de escena, hay algo más o menos inmutable elitrc los elementos externos, y cise es el lenguaje, en cuyo examen no podré detenerme corno quisiera. Debe señoblarse que dicho revelación deh argumento (el crimen y su expiación por culpables e inccentes) se da mediante imágenes y metároras referentes a enfermedacies, malestares, decaimiento corporal y descomposición del mundo físico y morál. La idea de una úlcera o tumor podrido domina tocio el lenguaje, lo ha dicho la perspicaz Caroline Spurgeon. El globo terráqueo está desquiciado, cree Hamlet, no solamente porque su madre es "la más inicua de las mujeres" y ama a quien es una "adúltera bestia... con pérfidas mañas... mañas malditas... (es) ese sapo, ese murciélago... la basura", sino porque entre elegir al padre de Hamlet, comparable a Apolo y Júpiter, "y un asesino y malvado, un miserable... un rey de farsa; un sálteador del reino y el poder, que robó de un anaquel la preciosa cliadema y se la metió en el bolsillo", ella prefirió al segundo, a este "rey de parches y remiendos", para vivir con él "entre el hediondo sudor de un lecho infecto, encenegado en la corrupción". Hamlet ve en el seno cle su madre "una 
encallecida úlcera, mientras la hedionda gangrena, minando el interior, lo (infecta) todo solapadamente". Aun el mismo fantasma dice que cuando su hermano le vertió el veneno en el oído, sintió que "una lepra vil invadia mi carne delicada, cubriéndola por completo de una infecia costra". Para Hamlet, Claudio es "la podreclumbre que contagió a su hermano bueno y sano": el uno es "la hermosa colina" y el otro "el cenagoso pantano"; a Ofelia le aconseja no ser madre de pecadores, pues en "la grosera sensualidad de los tiempos" que viven, cada hombre que nace sería un triunfo clel mal. La concepción, según él, es un acto infame: "si el sol engendra gusanos en un perro muerto, besando la carroña, siendo un dios..." ¿cómo, entonces, la mujer concebirá más limpiamente que el sol? Ante Polonio, entre burlas y veras, se queja de la decadencia moral cle la época: "ser honrado, tal como anda hov el mundo, equivale a ser escogido uno entre diez mil".

Los ciscursos de Hamlet refieren una lucha desigual entre el bien y el mal, y la corrupción y el hedor reinantes cuando triunfa el segundo. En esta lucha entre un hombre noble (su vencido padre) y un avispero de malvados, el más bellamente descrito de los últimos no es un personaje de la obra, sino la atroz figura de Pirro, el asesino de Príamo, un héroe legendario que brota en la competencia cle recitaciones entre Hamlet y uno de los actores. Pirro es, asi, el arquetipo del héroe victorioso e injusto, ante el cual los personajesevictoriosos etinjustos que rodean a

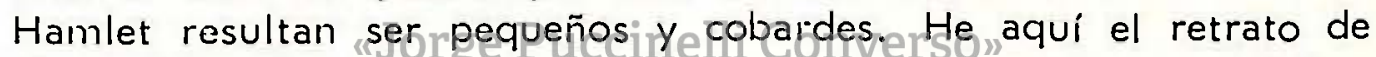
Pirro, "cuyas armas corvas, negras como su intento, semejaban la noche cuando yacía tendido sobre el fatal corcel; ahora muestra su horrenda y tenebrosa figura manchada de un blasón aún más fatídico. De pies a cabeza todo él es gules; teñido horriblemente con sangre de padres, madres, hijas e hijos, tostada y enfurecida por las hogueras de las calles incendiadas, que difunden una salvaje y diabólica luz a la matanza de su señor. Ardiendo en cólera y fuego y asi embadurnado de sangre coagulada, con unos ojos como carbunclos el infernal pirro corre en busca del anciano Príamo".

El mundo del deudo Hamlet es sangriento ¿quién lo niega? Pero sobre este mundo que empezó con un crimen y acabará en más crimenes, sobre cuya "masa inmunda y tosca, con triste as- 
pecto brilla horrorizado el sol", brota la ironia como la unica atmósfera en que puede sobrevivirse. Embebido el corazón en la ironia, a más de la incredulidad por los altos valores, la muerte pierde su sentido trágico y se vuelve una mueca o una burla del destino. Hamlet sonrie al decirnos que las cenizas del héroe Alejandro Magno sólo pueden servir para tapar un barril de cerveza. Quizá sea por su ánimo satírico que, si bien él mismo caiga varias veces en el crirnen, no se mancine como los demás; "es pepit? de oro entre un filón de vil metal"; afirma su madre.

Hamlet, debemos recordarlo, sólo es una pieza de teatro; no es un tratado de filosofia, ni de psicologia, ni de psiquiatria, ni de historia isabelina, ni de etica social. Pero en esta pieza teatral, aprovechando el método suelte $y$ fácil de la época, an que un dramaturgo solia detener lo acción para intercalar discursos sobre asuntos de intcrés general, Shakesteare se salió con frecuencia del tema para clarnos sus ideas sobre el hombre y el mundo. $Y$ en esta dispersión del tema reside ta fascinación intelectual y verbal de una obra cuyo conocimiento divide nuestras vidas en dos: atrás queda la persona opaca que fuimos antes de su lectura - representación, y aqui está la persona deslumbrada y henchida que somos después de conocerla.

\section{Biblioteca de Letras "Jorge Puccinelli Converso"}

